Revista de Matemática: Teoría y Aplicaciones 2005 12(1 \& 2) : 139-150

CIMPA - UCR - CCSS ISSN: 1409-2433

\title{
ARTIFICIAL NEURAL NETWORK PREDICTIONS OF WATER LEVELS IN A GULF OF MEXICO SHALLOW EMBAYMENT
}

\author{
Zack Bowles* $^{*} \quad$ Philippe E. Tissot ${ }^{\dagger} \quad$ Patrick Michaud ${ }^{\ddagger}$ \\ AleXey SADOVSKI ${ }^{\S}$
}

Received/Recibido: 9 Oct 2003

\begin{abstract}
Tide tables are the method of choice for water level predictions in most coastal regions. However, for many locations along the coast of the Gulf of Mexico, tide tables do not meet United States National Ocean Service (NOS) standards. Wind forcing has been recognized as the main variable not included. The performance of the tide tables is particularly poor in shallow embayments. Recent research has shown that Artificial Neural Network (ANN) models including input variables such as previous water levels, tidal forecasts, wind speed, wind direction, wind forecasts and barometric pressure can greatly improve over the tide charts for locations including open coast and deep embayments. In this paper, the ANN modeling technique is applied to a shallow embayment, the station of Rockport, located near Corpus Christi, Texas. The ANN model performance is compared against the NOS tide charts and the persistence model for the years 1997 to 2001. The performance is assessed using NOS criteria including Central Frequency (CF of $15 \mathrm{~cm}$ ), Maximum Duration of Positive Outliers (MDPO), and Maximum Duration of Negative Outliers (MDNO). Over the study period, the performances of the three models (tide table, persistence, ANN) are respectively CF's of $85 \%, 95.8 \%$ and $96.9 \%$, MDPOs of 16, 14 and 5.9 hours, and MDNOs of 72.8 hours, 0.6 and 9.5 hours.
\end{abstract}

Keywords: Neural networks, predictions, Water level, Texas Coastal Ocean Observation Network, Gulf of Mexico, harmonic analysis, tide charts, persistence model, forecasts.

\footnotetext{
${ }^{*}$ Texas A\& M University-Corpus Christi, Division of Nearshore Research, 6300 Ocean Dr,. NRC Suite 3400, Corpus Christi, TX 78412, U.S.A. E-Mail: zbowles@lighthouse.tamucc.edu.

${ }^{\dagger}$ Same address as Z. Bowles. E-Mail: ptissot@lighthouse.tamucc.edu.

${ }^{\ddagger}$ Same address as Z. Bowles. E-Mail: pmichaud@cbi.tamucc.edu.

${ }^{\S}$ Same address as Z. Bowles. E-Mail: sadovski@falcon.tamucc.edu.
} 


\section{Resumen}

Tablas de mareas son el método escogido generalmente para la predicción del nivel del agua en regiones costeras. Sin embargo, para muchas localidades en la costa del Golfo de México, las tablas de mareas no satisfacen las normas del Servicio Nacional Oceánico de los Estados Unidos (NOS, por sus siglas en inglés). La fuerza del viento ha sido reconocida como la principal variable no incluida. El rendimiento de las tablas de mareas es particularmente pobre en aguas poco profundas. Investigaciones recientes han mosrado que los modelos de redes de neuronas artificiales (ANN, por sus siglas en inglés) que incluyen variables de entrada como niveles previos de agua, previsiones de mareas, velocidad del viento, dirección del viento, predicción del viento, y presión atmosférica, pueden mejorar en gran medida los gráficos de mareas para localizaciones que incluyen mar abierto y aguas profundas. En este artículo, la técnica de modelación de ANN es aplicada a una estación de aguas poco profundas, la estación de Rockport, localizada cerca de Corpus Christi, Texas. El rendimiento del modelo ANN es comparado contra los gráficos de mareas NOS y el modelo de persistencia para los años 1007 a 2001. El rendimiento es medido usando los criterios NOS, que incluyen Frecuencia Central (FC de $15 \mathrm{~cm}$ ), Máxima Duración de Puntos Atípicos Positivos (MNPO), y Máxima Duración de Puntos Atípicos Necagativos (MDNO). Sobre el período de estudio, el rendimiento de los tres modelos (tabla de mareas, persistencia, ANN) son, respectivamente, $\mathrm{CF}$ de $85 \%, 95.8 \%$ y $96.9 \%$, para MDPO es 16,14 y 5.9 horas, y para MDNO es de $72.8,0.6$ y 0.5 horas.

Palabras clave: Redes neuronales, predicciones, nivel del agua, Red de Observación Oceánica de la Costa de Texas, Golfo de México, análisis armónico, gráficos de mareas, modelo de persistencia, previsiones.

Mathematics Subject Classification: 62M45.

\section{Introduction}

In recent years the importance of marine activities has grown steadily. With the growth of the economy the shipping industry has seen its activity increase leading to a push towards larger deeper draft vessels. The operation of such vessel would greatly benefit from accurate advanced water level related information. The coastal communities at large would greatly benefit from such forecasts as well, especially during tropical storm events. A comparison of measured water levels with tidal forecasts is presented in Figure 1. The research team at Texas A\&M University-Corpus Christi, Division of Nearshore Research, has taken on two main tasks: the design of a model that will provide more accurate results than the currently relied upon tide charts, and to make the results from this model accessible to the marine community.

The area of interest for this work is Rockport, TX. Rockport is a coastal community of 7385 people, and at its maximum elevation is only two meters (approximately five feet) in height [2]. In general, all of the tourist activities, restaurants, and entertainment facilities are located near the water, no more than a few inches above the water level in Aransas Bay, a particularly shallow embayment (See Figure 2).

Several approaches have been considered to solve the task of providing a more accurate model. One approach considered was Multivariate Statistical Analysis, which focuses on 


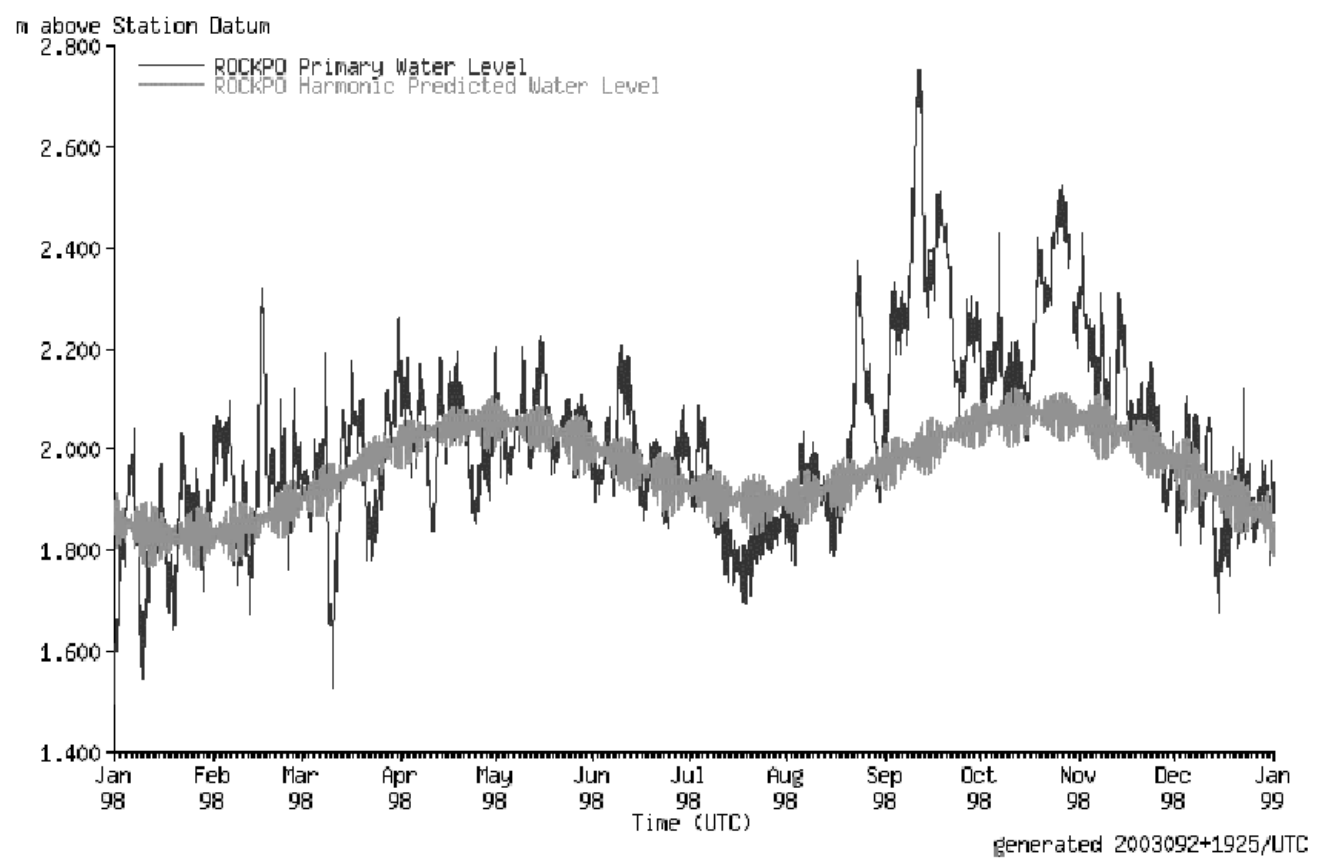

Figure 1: Comparison of the Rockport Tide Chart predictions (gray) and the actual water level measurements (black) in 1998. Notice the discrepancy between the predicted and actual values.

linear regression models coupled with harmonic analysis of the astronomical forces causing the tides [3]. This work was focused on the other main technique investigated: Artificial Neural Networks. To date, the Artificial Neural Network models have provided more accurate results for open coast and deeper embayments, but had not been tested for such shallow embayment. The Artificial Neural Networks took into account the astronomical tide information in addition to time series of measured water levels, wind speeds and wind directions and barometric pressures.

The input data had been queried from data compiled for more than 10 years in the real-time database of the Texas Coastal Ocean Observation Network [4] (See Figures 3,4). The models were trained over large data sets, and all the results were then compared using the National Ocean Service skill assessment statistics, with an emphasis on the Central Frequency. Central Frequency is the ratio of predictions that are within plus or minus X $\mathrm{cm}$ from the actual measurement. For NOS to consider a model operational, its Central Frequency of $15 \mathrm{~cm}$ must be equal or greater than $90 \%$. The tide charts (the current method of water level predictions) for the entire coast of Texas did not pass the standard (see Figure 5). The deficiency of the tide charts and its cause are known as the National Oceanic and Atmospheric Administration (NOAA) stated, for example, that "presently published predictions do not meet working standards" when assessing the performance of the tide charts for Aransas Pass, Texas [5,6].

The first test for a new model to be accepted is that it must improve upon the perfor- 


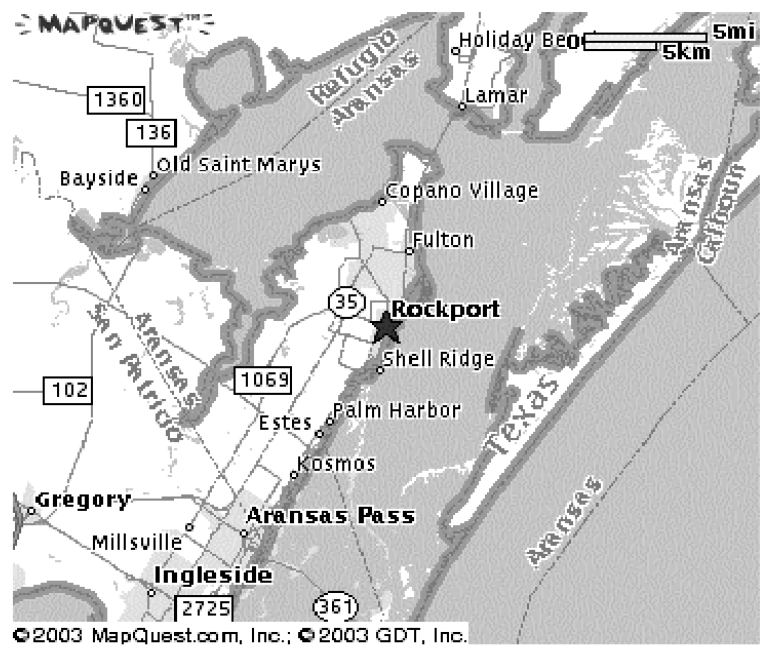

Figure 2: Rockport, TX. The city is located 35 miles from Corpus Christi, one of the nations most active ports.

mance of a benchmark model called the persisted difference or "Persistence" model. The persistence model relies on the inference that a presently observed distance between the tide chart prediction and the actual water level will persist into the future. The Persistence model basically takes an offset and applies it to the tide charts for the prediction. It is simple and yet considerably more effective than the tide charts in predicting water levels along the Texas Gulf coast. Once this benchmark was incorporated, the objective shifted to the development and assessment of an ANN model applied to various locations along the Gulf Coast and within shallow estuaries and embayments.

\section{Site description, methodology and model}

As mentioned previously, the focus of this study was a small coastal town named Rockport, TX. Rockport is most directly affected by Aransas Bay, which is linked to the Gulf of Mexico through Aransas Pass (See Figure 2). The barrier island protecting Rockport from the effects of the Gulf is called San Jose Island, which is also connected to Matagorda Island. The shallow waters between the barrier islands and the Rockport coastline lead to a delay between the observed water level trends in the Gulf and in Rockport. In general, what is observed in the Gulf takes a few hours to register in the affected bays. Most of the directly observed water level changes had been correlated with strong winds and frontal passages $[7,5,6]$. This made it important to test the inclusion of winds as part of the input to the ANN model, but many other factors must also be considered. The presently used Artificial Neural Network model includes previous water levels measurements, tidal forecasts, previous wind speed and wind direction measurements, wind forecasts, and 


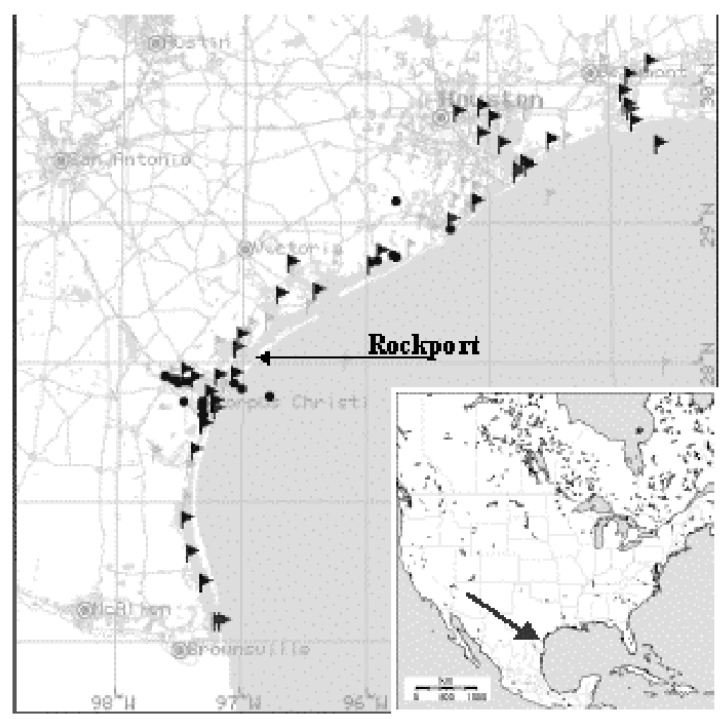

Figure 3: The Texas Coastal Ocean Observation Network (TCOON). Over 50 stations relay real-time environmental and oceanographic data for observations of the Gulf Coast.

barometric pressure. A schematic of the model is presented in Figure 6. Although a plethora of other time series data is available, it was shown through factor analysis that only a few components were actually necessary to model the water level changes [3]. Five years of hourly data between 1997 and 2001 were chosen to train and test the ANN model. Less than $2 \%$ of the data was missing for each one of the data series (See table 1) used in this work except for the Bob Hall Pier 1999 data set where 2.2\% of the wind data was missing. The gaps were filled by linear interpolation within the gaps for wind data and for water level gaps, the tidal component of the water level was first subtracted, then the gap was filled by interpolation, and finally the tidal component was added back in. All water level measurements were in reference to mean lower low water levels because the main audience for our predictions was ship captains, and many nautical charts use this as their reference point. The tidal forecasts, water levels, and all meteorological data were downloaded from the Texas Coastal Ocean Observation Network database. The tide forecasts were computed using a years worth of water level data and 26 harmonic constituents, using NOAA procedures [8]. The information from the different inputs was scaled to a $[-1.1,1.1]$ range and inserted into the first layer of an Artificial Neural Network called the hidden layer (See figure 6). A set of random numbers was picked to start the training process, then weights and biases were progressively optimized to adjust to the desired output or target. The number of layers could be varied with each case, but previous studies [1,9] in Galveston Bay and Corpus Christi Bay showed that simple Artificial Neural Networks using only one hidden and one output layer were the most effective.

All ANN models had been developed, trained, tested, and assessed in the MatLab R13 environment and using the Neural Network Toolbox [10]. The computers using MatLab ranged in processor speed from $450 \mathrm{MHz}$ to $2.6 \mathrm{GHz}$. The Levenberg-Marquardt algorithm 


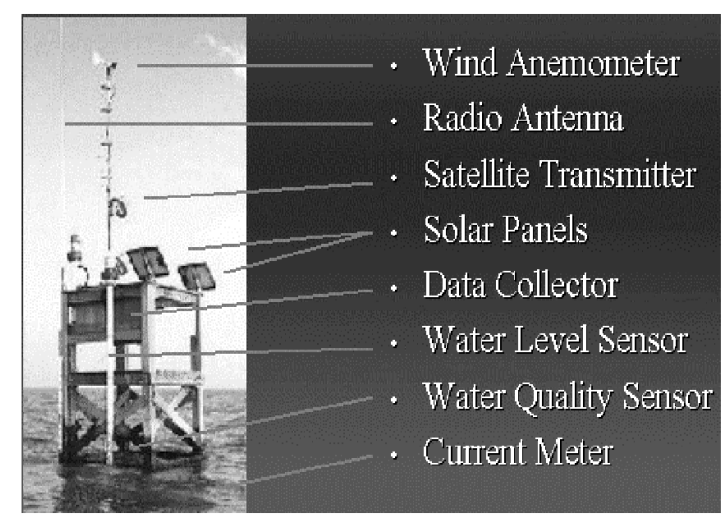

Figure 4: A typical TCOON station. Each station records a variety of time series data then transmits the data to the TCOON database.

found in the Neural Network Toolbox was used to train the ANN model. The model was trained over one year of data, then applied to the other four years to create five training sets and twenty testing sets. The average performances were computed over the testing sets. The effectiveness of the models were determined using the National Ocean Service skill assessment statistics(See table 2)

\begin{tabular}{c|cccc}
\hline \hline \multirow{2}{*}{$\begin{array}{c}\text { Data Set } \\
\text { Year }\end{array}$} & Data Set Span & Data Available & $\begin{array}{c}\% \text { pwl } \\
\text { Missing }\end{array}$ & $\begin{array}{c}\text { Max Dur Miss } \\
\text { Data (pwl) }\end{array}$ \\
\hline 1996 & $1 / 1 / 96-12 / 31 / 96$ & pwl, wtp, harmwl, sig & $1.40 \%$ & 112 pts. \\
1997 & $1 / 1 / 97-12 / 31 / 97$ & pwl, wtp, harmwl, sig & $0.53 \%$ & 22 pts. \\
1998 & $1 / 1 / 98-12 / 31 / 98$ & pwl, wtp, harmwl, sig & $0.43 \%$ & 23 ts. \\
1999 & $1 / 1 / 99-12 / 31 / 99$ & pwl, wtp, harmwl, sig & $0.13 \%$ & 4 pts. \\
2000 & $1 / 1 / 00-12 / 31 / 00$ & pwl, wtp, harmwl, sig & $0.14 \%$ & 7 pts. \\
2001 & $1 / 1 / 01-12 / 31 / 01$ & pwl, wtp, harmwl, sig & $0.05 \%$ & 1 pt. \\
\hline \hline
\end{tabular}

Table 1: Availability of data for the Rockport station from 1996-2001, and a summary of the missing data.

\section{Optimization and application}

The first step in the optimization of the Artificial Neural Network was to find the number of previous water levels optimizing the accuracy of the water level forecasts. The average Central Frequency (CF) was used to evaluate the accuracy of the forecast. Previous water levels were added to the model in increments of three previous hours until the optimum $\mathrm{CF}$ was reached for that forecast, then the same process was repeated for increased forecasting times. Once the optimum number of previous water levels was found, the typical 


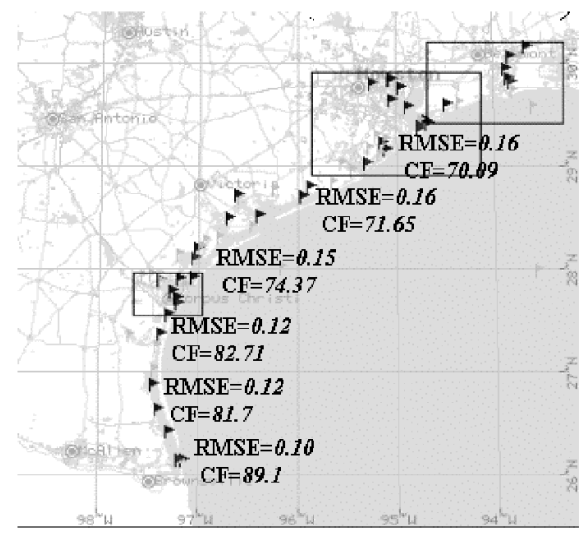

Figure 5: Comparison of six coastal stations and their respective RMSE and Central Frequency for the tide charts. The NOS standard is $90 \%$, and the best value is $89.1 \%$.

\begin{tabular}{c|r}
\hline \hline Error & The predicted value $p$ minus the observed value $r$ \\
SM & Series Mean; the mean value of a time series $y$ \\
RMSE & Root Mean Square Error \\
SD & Standard Deviation \\
$\mathrm{CF}(X)$ & Central Frequency; \% of errors within the limits of $-X$ and $X$ \\
$\operatorname{POF}(2 X)$ & Positive Outlier Frequency, \% of errors greater than $X$ \\
$\operatorname{NOF}(2 X)$ & Negative Outlier Frequency; $\%$ of errors less than $-X$ \\
$\operatorname{MDPO}(2 X)$ & Maximum Duration of Positive Outliers \\
$\operatorname{MDNO}(2 X)$ & Maximum Duration of Negative Outliers \\
\hline \hline
\end{tabular}

Table 2: NOS Skill assessment statistics. The Central Frequency is the main performance assessment.

methodology would have been to include previous winds. However, since the Rockport station did not have wind data during the time of study this step was eliminated. The next step in the optimization was to find the best number of previous water levels for another nearby station considered, starting with Bob Hall Pier, an open coast station. The same process was used for these previous water levels until the best combination of water levels from Bob Hall Pier and Rockport was found. Then, using the optimal water levels from Rockport, the third station, Port Aransas, was also evaluated. Once again, previous water levels were increased until the optimum number was found. Bob Hall Pier and Port Aransas have complete wind data, so once the optimal water levels were established, the winds for these stations could be incorporated into the model. Previous winds were added in the same fashion as water levels: increasing the number of previous winds by three hours at a time until the optimum or 48 hours previous is reached. The final step in optimization was incorporating the wind forecasts. In the operational models the wind 


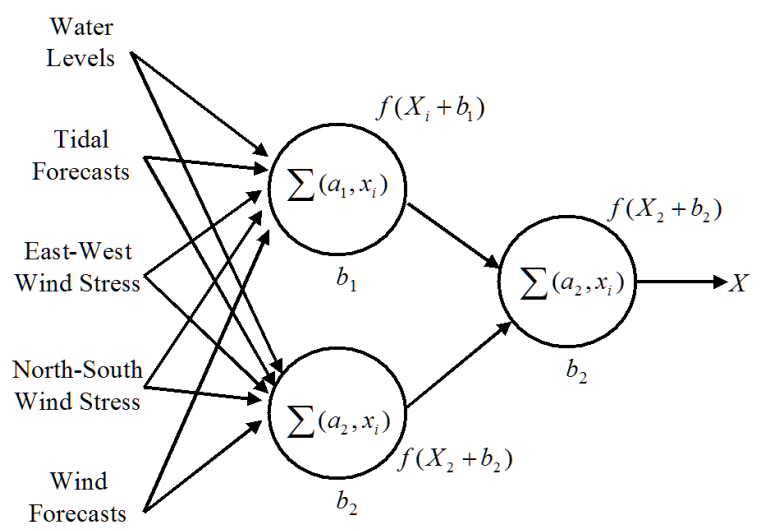

Figure 6: An example of a typical Artificial Neural Network with an input deck of five components, two hidden layers and one output layer.

forecasts will be provided by the National Center for Environmental Predictions (NCEP) Eta-12 model. However, a historical database of past forecasts did not exist. For the purpose of this study, wind forecasts were created using the actual wind measurements. The performance of the ANN for the Rockport station was significantly improved when the wind forecasts from Bob Hall Pier were included, but not when including wind forecasts from the Port Aransas station. Changing the number of neurons was also a possibility in finding the optimized model, but previous studies [11] showed no significant improvement in the results. In general more accurate forecasts were observed when larger numbers of previous water levels were used. The optimal ANN model changes slightly for different forecasts times, but in general, using 24 hours of previous water levels at Rockport, 24 hours of previous water levels at Bob Hall Pier, and 12 hours of previous wind speeds and wind directions at Bob Hall Pier lead to the most accurate water level forecasts without using wind forecasts. This model resulted in a $\mathrm{CF}(15 \mathrm{~cm})$ of $99.59 \%$ for a 3-hour forecast, $99.20 \%$ for a 12 -hour forecast, $97.85 \%$ for a 24 -hour forecast, and $91.33 \%$ for a 48 -hour forecast. Even for a two-day water level forecast, the model stays about $1.3 \%$ above the NOS criteria for a successful model or $90 \%$. The tide charts, however had a $\mathrm{CF}(15 \mathrm{~cm})$ of $85 \%$, and the Persistence Model, $87.18 \%$ for 48 -hour forecasts. Both of which were below the standard for an acceptable model. Adding the Bob Hall Pier wind forecasts to the model increased the CF by 3.6\% (See Figure 7) which emphasized the importance of having wind forecasts available for the operational model.

\section{Discussion}

The performance of the ANN at the Rockport station was to improve significantly upon all other discussed models. The $91.33 \%$ CF for 48-hour forecasts is a significant improvement 


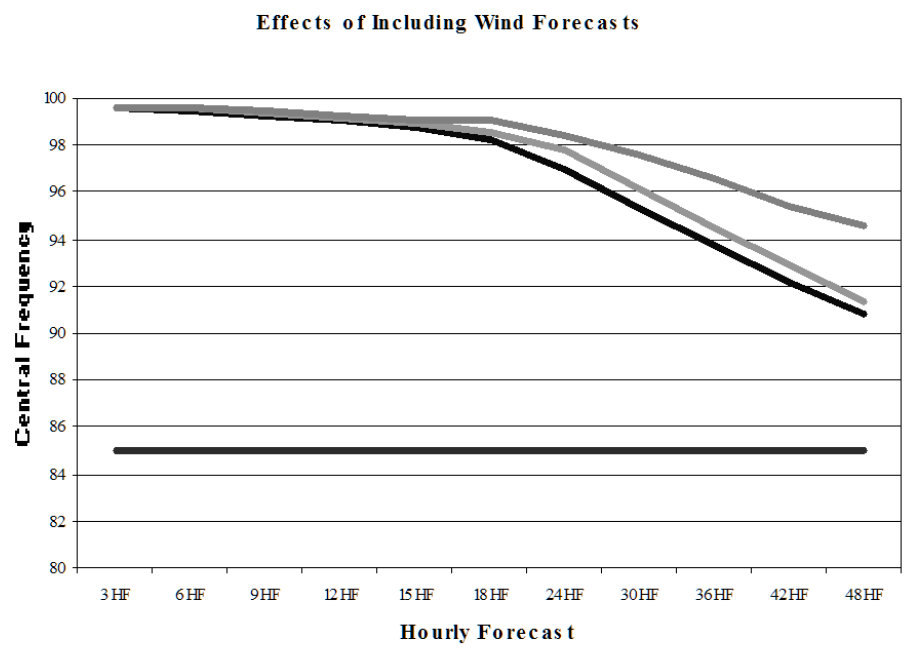

Figure 7: The effects of the inclusion of wind forecasts. The top line is the ANN model using Rockport previous water levels, Bob Hall Pier previous water levels and wind measurements, and Bob Hall Pier wind forecasts, which led to an increase in $\mathrm{CF}(15 \mathrm{~cm})$ of $3.5 \%$. The second line is using information from Port Aransas, and the third line is using information from Rockport only. The bottom line is the tide chart prediction.

over the other models considered $(85 \%$ for the tide charts and $87 \%$ for the Persistence model). It was interesting to find that data from Bob Hall Pier was more helpful in improving forecasts than data at Port Aransas, likely because geographically, Port Aransas is closer to Rockport and also shielded from the Gulf of Mexico by the barrier islands. In particular, the wind data at Port Aransas is affected by the island and the ship channel, or Aransas Pass has a dampening effect on the water level changes. The importance of winds can be observed in the increase in accuracy when this information is added to the model. A $0.4 \%$ increase in $\mathrm{CF}$ was observed when wind data was incorporated, and although this seems like a small difference, practically this represents an additional day and a half for which the predictions will be within the $\pm 15 \mathrm{~cm}$ range. When wind forecasts were used there was a $3.6 \%$ increase in effectiveness which corresponds to an additional 13 days of acceptable water level predictions. Archived wind forecasts were not available throughout this research, so the forecasts were obtained from actual measurements. The real-time model will utilize the Eta-12 wind forecast database, made available through a collaboration with the Corpus Christi Weather forecasting Office [12]. These forecasts have already been tested in a separate study of three local stations: Bob Hall Pier, Naval Air Station, and Port Aransas [13]. This study and a related one on Galveston Island [14] showed that the difference between wind forecasts and wind measurements was not significant for the model, and that the water level predictions were not significantly affected by the likely differences between forecasts and measurements. Incorporating accurate wind forecasts will be particularly important when predicting water levels during frontal passages. The ANN has difficulty in catching very rapid changes in water levels without the association of wind forecasts during sudden changes in wind speeds and wind directions. The application of the ANN to tropical storms and frontal passages was also found to 
be very effective for up to 24-hour forecasts for the case of Tropical Storm Frances (See figure 7). Throughout this storm, the Neural Network stayed within $10 \mathrm{~cm}$ of the water level most of the time, and at its worst, was off by about $18 \mathrm{~cm}$ (just over half a foot). The application of the model to tropical storms is being studied, but caution should be exercised as each storm is unique.

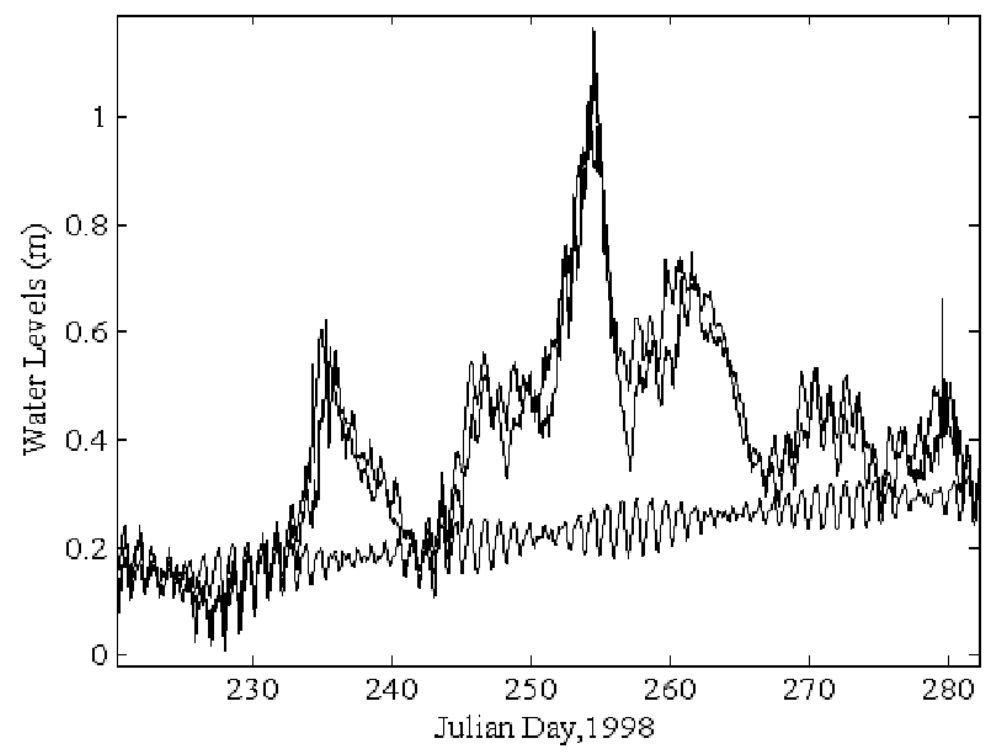

Figure 8: The performance of the ANN during Tropical Storm Frances. This model was trained on data from 1997, then applied to 1998. Black is the ANN performance, underlying gray is actual water levels, and the harmonic pattern on the bottom is the tide chart prediction.

\section{Conclusions}

The Rockport station was the first shallow water station that the Division of Nearshore Research tested its ANN models on. The results showed that the ANN outperforms all present models for the Rockport station (See Table 3). The tide charts and the Persistence models do not meet the NOS criteria, while the Linear Regression model and the Neural Network Models (one with wind forecasts and one without) showed accuracy above the 90\% CF criteria with the ANN model including wind forecasts having the best performance at $94.5 \%$. The effectiveness of the model shows that a strong correlation can be established between water level forecasts and meteorological factors. The optimal model is a combination of the previous water levels at both Rockport and Bob Hall Pier, and previous wind information from the same coastal station. In this case, 24 hours of previous water levels at both Rockport and Bob Hall Pier, and 12 hours of previous winds at Bob 
Hall Pier. Wind forecasts significantly improve the water level forecasts and efforts are being made to incorporate Eta-12 wind information into the model. The success of the ANN model during Tropical Storm Frances was intriguing and somewhat unexpected, and provides incentives for the development of new storm models. Other further developments include the use of engineered training sets. Such custom made training sets could provide the ANN's with a higher density of storms and therefore a better performance during such weather events. The simplicity and effectiveness of the tested Artificial Neural Network models has shown that this powerful and flexible modeling technique should benefit the marine community when models will be made available via the World Wide Web in late Fall, 2003.

\begin{tabular}{c|cccccc}
\hline \hline Model & RMSE & CF & POF & NOF & MDPO & MDNO \\
\hline Harmonic & $0.11 \pm 0.02$ & $85.02 \pm 4.12$ & $0.21 \pm 0.19$ & $1.90 \pm 2.51$ & $16 \pm 16$ & $73 \pm 81$ \\
Pers 24hr & $0.069 \pm 0.006$ & $95.75 \pm 1.19$ & $0.249 \pm 0.231$ & $0.023 \pm 0.029$ & $14 \pm 19.17$ & $0.6 \pm 1.342$ \\
NN-1 24hr & $0.0588 \pm 0.0085$ & $97.848 \pm 1.515$ & $0.132 \pm 0.114$ & $0.104 \pm 0.232$ & $8.5 \pm 8.7$ & $7.6 \pm 18.5$ \\
NN-2 24hr & $0.053 \pm 0.0079$ & $98.563 \pm 1.284$ & $0.124 \pm 0.115$ & $0.08 \pm 0.204$ & $8.4 \pm 8.7$ & $6.2 \pm 17.1$ \\
Pers 48hr & $0.101 \pm 0.009$ & $87.18 \pm 2.22$ & $0.785 \pm 0.528$ & $0.424 \pm 0.255$ & $25.4 \pm 17.813$ & $13.8 \pm 10.232$ \\
NN-1 48hr & $0.0889 \pm 0.0123$ & $91.396 \pm 2.768$ & $0.199 \pm 0.158$ & $0.57 \pm 0.937$ & $9.6 \pm 7.6$ & $26.4 \pm 37.7$ \\
NN-2 48hr & $0.0779 \pm 0.0108$ & $94.500 \pm 2.616$ & $0.123 \pm 0.162$ & $0.299 \pm 0.575$ & $6.8 \pm 9.6$ & $16.3 \pm 30.7$ \\
\hline \hline
\end{tabular}

Table 3: Comparison of the present models. The Central Frequency is the main skill assessment used, and it is shown that the ANN model outperformed the other models in all cases.

\section{Acknowledgements}

NASA Grant \# NCC5-517; National Oceanic and Atmospheric Administration (NOAA); Texas General Land Office (TGLO); Coastal Management Program (CMP); Division of Nearshore Research (DNR), Website: http://lighthouse.tamucc.edu.

\section{References}

[1] Cox, D.T.; Tissot, P.E.; Michaud, P.R. (2002a) "Water level observations and shortterm predictions including meteorological events for the entrance of Galveston Bay, Texas", J. of Wtwy, Port, Coast., and Oc. Engrg. 128(1): 21-29.

[2] Info on Rockport elevation:

http://www. travelbyroad.net/trip_planner/p_09750_2800_cty.

[3] Sadovski, A.L.; Tissot, P.; Michaud, P.; Steidley, C. "Statistical and neural network modeling and predictions of tides in the shallow waters of the Gulf of Mexico", WSEAS Transactions on Systems 2(2): 301-307.

[4] Michaud P.R.; Jeffress, G.; Dannelly, R.; Steidly, C. (2001) "Real-time data collection and the Texas Coastal Ocean Observation Network", in: Proc. of Intermac '01 Joint Technical Conference, Tokyo, Japan. 
[5] NOAA (1991) "NOAA Technical Memorandum NOS OMA 60", National Oceanic and Atmospheric Administration, Silver Spring, Maryland.

[6] NOAA (1994) "NOAA Technical Memorandum NOS OES 8", National Oceanic and Atmospheric Administration, Silver Spring, Maryland.

[7] Garvine, R. (1985) "A simple model of estuarine subtidal fluctuations forced by local and remote wind stress", J. Geophys. Res. 90(C6): 11945-11948.

[8] Mostella, A.; Duff, J.S.; Michaud, P.R. (2002) "Harmpred and Harman: web-based software to generate tidal constituents and tidal forecasts for the Texas Coast", in: Proc. of the 19th AMS Conf. on Weather Analysis and Forecasting/15th AMS Conf. on Numerical Weather Prediction, 12-16 August 2002, San Antonio, Texas.

[9] Tissot P.E.; Cox, D.T.; Michaud, P. (2002) "Neural network forecasting of storm surges along the Gulf of Mexico", in: Proc. of the Fourth International Symposium on Ocean Wave Measurement and Analysis (Waves '01), Am. Soc. Civil Engrs.: 15351544 .

[10] The MathWorks, Inc. (1998) Neural Network Toolbox for use with Matlab 5.3/version 3. The MathWorks, Natick, MA.

[11] Tissot, P.E.; Michaud, P.R.; Cox, D.T. (2003) "Optimization and performance of a neural network model forecasting water levels for the Corpus Christi, Texas, Estuary", in: 3rd Conference on the Applications of Artificial Intelligence to Environmental Science, Long Beach, California, February 2003.

[12] Patrick, A.R.; Collins, W.G.; Tissot, P.E.; Drikitis, A.; Stearns, J.; Michaud, P.R. (2002) "Use of the NCEP MesoEta Data in a water level predicting neural network", in: Proc. of the 19th AMS Conf. on Weather Analysis and Forecasting/15th AMS Conf. on Numerical Weather Prediction, 12-16 August 2002, San Antonio, Texas: 369-372.

[13] Stearns, J.; Tissot, P.E.; Michaud, P.R.; Patrick, A.R.; Collins, W. G. (2002) "Comparison of MesoEta wind forecasts with TCOON measurements along the Coast of Texas", in: Proc. of the 19th AMS Conf. on weather Analysis and Forecasting/15th AMS Conf. on Numerical Weather Prediction, 12-16 August 2002, San Antonio, Texas: J141-J144.

[14] Cox, D.T.; Tissot, P.E.; Michaud, P.R. (2002b) "Statistical hindcasts and the relative importance of local and remote forcing on subtidal variability in Galveston Bay, Texas", J. Geophys. Res., submitted. 